\title{
Highly Concentrated Autologous Platelet-Rich Plasma Restores Foveal Anatomy in Lamellar Macular Hole Surgery
}

\section{Hochkonzentriertes autologes Thrombozytenkonzentrat verbessert die foveale Anatomie in der chirurgischen Therapie von Makulaschichtforamina}

Authors

Felix Hagenau ${ }^{\mathbb{(}}$, Matthias Nobl, Denise Vogt, Benedikt Schworm, Jakob Siedlecki ${ }^{\mathbb{D}}$, Thomas Kreutzer, Nikolaus Luft, Siegfried Priglinger

\section{Affiliation}

Department of Ophthalmology, Ludwig Maximilians University of Munich, Munich, Germany

\section{Key words}

lamellar macular hole, platelet-rich plasma, vitrectomy, peeling, retina

\section{Schlüsselwörter \\ Makulaschichtforamen, Thrombozytenkonzentrat, Vitrektomie, Peeling, Retina}

$\begin{array}{ll}\text { received } & 12.12 .2020 \\ \text { accepted } & 18.2 .2021 \\ \text { published online } & 17.5 .2021\end{array}$

Bibliography

Klin Monatsbl Augenheilkd 2021; 238: 885-892

DOI 10.1055/a-1409-9268

ISSN 0023-2165

(c) 2021. Thieme. All rights reserved.

Georg Thieme Verlag KG, Rüdigerstraße 14,

70469 Stuttgart, Germany

Correspondence

Prof. Siegfried Priglinger

Klinikum der Universität München Augenklinik,

Ophthalmology

Mathildenstraße 8, 80336 Munich, Germany

Phone: + 49(0) 89440053800 , Fax: + 49(0) 89440054778

s.priglinger@med.uni-muenchen.de

\section{ABSTRACT}

Background Lamellar macular holes (LMHs) are an entity of a progressive disease in which the efficacy of the therapy of choice, vitrectomy, seems to be reduced. It is unknown whether highly concentrated autologous platelet-rich plasma (PRP) is of value in the therapy of LMHs. The purpose of this study was to gauge the potential of highly concentrated PRP to restore foveal anatomy in LMH surgery.
Patients and Methods In this interventional case series, eight eyes of eight patients with progressive LMH were included. All patients underwent a 23 -gauge pars plana vitrectomy with induction of a posterior vitreous detachment and peeling of tractive epiretinal membranes whenever present. Under air tamponade, $0.1 \mathrm{~mL}$ of highly concentrated autologous PRP was applied. Subsequently, a gas or air tamponade was performed. All patients were instructed to rest in the supine position for the first 1 to 2 postoperative hours. Bestcorrected visual acuity (BCVA) testing, microperimetry, spectral-domain optical coherence tomography (SD-OCT) and fundus photography were performed prior to and 3 months after surgery.

Results SD-OCT showed closure of the macular defect with restoration of a normal foveal configuration in all (8 of 8 ) patients 3 months postoperatively. BCVA improved significantly, from $0.28 \pm 0.08$ to $0.12 \pm 0.14 \log$ MAR (Wilcoxon: $p=0.03$ ) Microperimetry remained unchanged $(24.13 \pm 1.96$ vs. $23.7 \pm 1.54 \mathrm{~dB} ; \mathrm{p}=0.46$ ). No clinically significant intra- or postoperative complications were observed.

Conclusion The use of highly concentrated PRP enables excellent anatomical and functional outcomes in the surgical therapy of $\mathrm{LMH}$. Further prospective comparative trials are warranted to compare this promising technique with existing surgical strategies.

\section{ZUSAMMENFASSUNG}

Hintergrund Makulaschichtforamina sind eine progrediente Erkrankung, bei der die Wirksamkeit der Therapie der Wahl, der Vitrektomie, reduziert zu sein scheint. Das Potenzial von hochkonzentriertem autologem Thrombozytenkonzentrat (Platelet-rich Plasma, PRP) in der Therapie von Makulaschichtforamina ist unbekannt. Ziel dieser Studie ist die Beurteilung des Potenzials von hochkonzentriertem autologem Thrombozytenkonzentrat in der chirurgischen Therapie von Makulaschichtforamina.

Patienten und Methoden In diese interventionelle Fallserie wurden 8 Augen von 8 Patienten mit progressivem LMH eingeschlossen. Alle Patienten erhielten eine 23-Gauge-Pars- 
plana-Vitrektomie mit Induktion einer hinteren Glaskörperabhebung und Peeling traktiver epiretinaler Membranen, sofern vorhanden. Unter Lufttamponade wurde 0,1 ml hochkonzentriertes autologes Thrombozytenkonzentrat appliziert. Anschließend wurde eine Gas- oder Lufttamponade eingegeben. Alle Patienten wurden angewiesen, in den ersten 1-2 postoperativen Stunden in Rückenlage zu ruhen. Der bestkorrigierte Visus (BCVA), Mikroperimetrie, optische Kohärenztomografie (SD-OCT) und die Fundusfotografie erfolgten präoperativ sowie 3 Monate postoperativ.

Ergebnisse In der SD-OCT zeigte sich einen Verschluss des Makuladefekts mit Wiederherstellung der normalen fovealen Konfiguration bei allen ( 8 von 8 ) Patienten 3 Monate post- operativ. Die bestkorrigierte Sehschärfe verbesserte sich signifikant von $0,28 \pm 0,08$ auf $0,12 \pm 0,14 \log M A R$ (Wilcoxon: $p=0,03)$. Die Mikroperimetrie blieb stabil $(24,13 \pm 1,96$ vs. $23,7 \pm 1,54 d B ; p=0,46)$. Es wurden keine klinisch signifikanten intra- oder postoperativen Komplikationen beobachtet. Schlussfolgerung Die Verwendung von hochkonzentriertem autologem Thrombozytenkonzentrat ermöglicht hervorragende anatomische und funktionelle Ergebnisse in der chirurgischen Therapie der Makulaschichtforamina. Weitere prospektive Vergleichsstudien sind notwendig, um diese vielversprechende Technik mit bestehenden chirurgischen Strategien zu vergleichen.

\section{Introduction}

Gass first described the entity of lamellar macular holes (LMHs) in the 1970 s as a complication of cystoid macular edema after cataract extraction [1]. LMHs often show a stable condition over time but can also lead to a progressive decrease in visual acuity as well as increasing metamorphopsia [2]. In a recent publication, Hubschman et al. updated and specified the classification of LMHs using spectral-domain optical coherence tomography (SD-OCT) [3]. To diagnose an LMH, three mandatory criteria must be visible on SD-OCT: an irregular foveal contour, a foveal cavity with undermined edges, and a sign of foveal tissue loss. Especially in LMH with a longer history, further associated signs on SD-OCT can be a foveal bump, a disruption of the ellipsoid zone, or epiretinal proliferation (ERP) [3].

The latter was first described in 2014 by Pang et al. as lamellar hole-associated epiretinal proliferation (LHEP), an iso- to hyporeflective material without tractive properties in OCT [4]. As LHEP can, however, also be detected in other diseases of the vitreoretinal interface, the term ERP is favored by some authors [3]. The presence of this hypodense proliferation is associated with a more frequent occurrence of photoreceptor layer defects, corresponding to poorer visual acuity, and increases in LHEP surface have been associated with increases in intraretinal cleavage, which currently represents the most reliable parameter of progression [5, $6]$. Using multimodal imaging, tractive foveal or extrafoveal epiretinal membranes are also often found in LMHs, which may accelerate LMH progression by exerting tangential traction forces [7].

Currently, vitrectomy with removal of epiretinal tissue and the internal limiting membrane (ILM) represents the therapy of first choice in LMHs. As opposed to full thickness macular holes (FTMHs) or macular pseudoholes, in which vitrectomy can be performed with high efficacy and safety, LMHs, however, represent an entity in which the efficacy of vitrectomy seems to be reduced, especially in advanced degenerative cases with ellipsoid zone defects and missing tractional forces $[2,8]$. Therefore, vitrectomy in $\mathrm{LMH}$ is often delayed, and results are poor.

In 2019, Gonzales et al. published a small case series of three patients suffering from vitreoretinal interface diseases that were treated by vitrectomy without epiretinal membrane peeling with application of autologous platelet-rich plasma (PRP) [9]. The re- sults showed a promising restitution of foveal morphology and retinal function. However, due to the small number of patients and their rather atypical and heterogeneous preoperative LMH morphology profile on SD-OCT, the efficacy of PRP in LMH surgery warrants further investigation. Thus, the purpose of the present study was to elucidate the safety of highly concentrated autologous PRP and whether PRP might have an effect on the outcome of vitrectomy in a series of clearly characterized LMHs.

\section{Materials and Methods}

In this interventional, prospective case series, we included eight eyes of eight patients undergoing vitrectomy with adjuvant foveal application of highly concentrated autologous PRP for symptomatic and progressive LMH. Surgery was performed between December 2019 and May 2020 at the Department of Ophthalmology, Ludwig Maximilians University of Munich, Germany, by two highly experienced retinal surgeons (S.G.P., T.C.K.). This study was approved by the institutional review board of the University Eye Hospital of the Ludwig Maximilians University and was conducted in accordance with the tenets outlined in the Declaration of Helsinki. All subjects gave written informed consent to undergo the interventions outlined in detail below.

\section{Patient selection}

The diagnosis of $\mathrm{LMH}$ was made by clinical examination and SD-OCT imaging, in which all three of the established mandatory criteria had to be fulfilled: (1) an irregular foveal contour, (2) a foveal cavity with undermined edges, and (3) a sign of foveal tissue loss [3]. Patients with confounding retinal pathology such as diabetic retinopathy, vitreous hemorrhage, retinal detachment, agerelated macular degeneration, inflammatory disease, vascular occlusion, high myopia (<-6.00 dpt), or trauma were excluded. Recommendation for vitrectomy was based on a progression in morphology and/or a significant decrease in visual acuity during the preoperative follow-up period and/or significant impairment of quality of daily life by metamorphopsia.

\section{Preoperative and postoperative examinations}

Subjective manifest refraction was measured using the Jackson cross-cylinder method and best-corrected distance visual acuity 


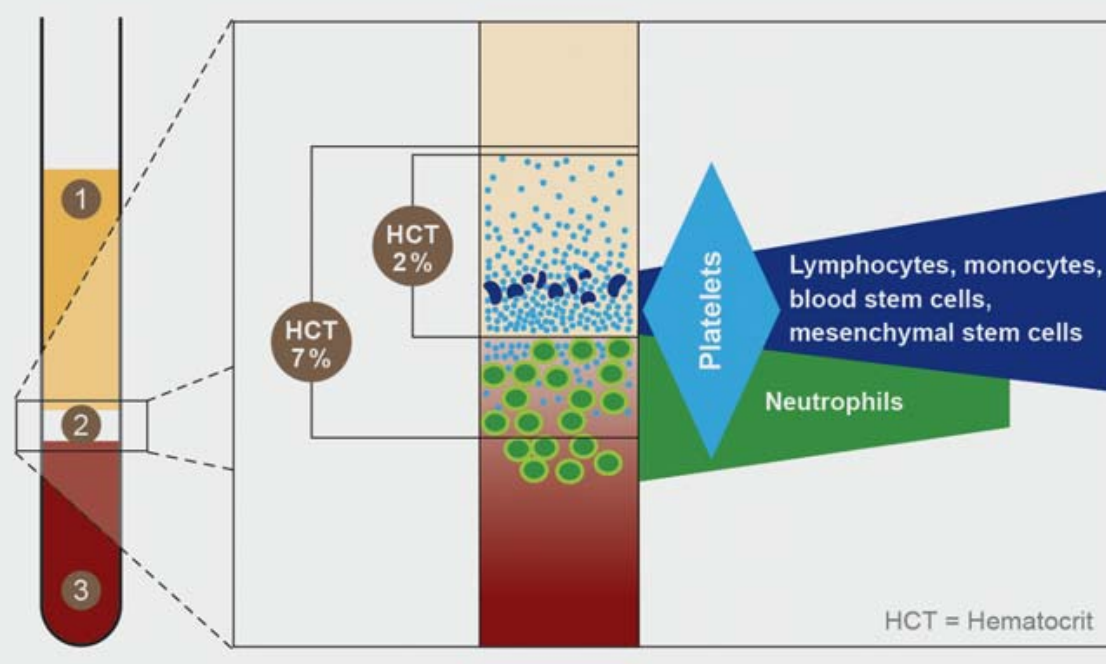

(1) Platelet-poor plasma

(2) Buffy coat

(3) Erythrocyte-enriched fraction

- Fig. 1 Representation of the blood components and the fraction of the buffy coat (2) obtained for the production of the highly concentrated platelet-rich plasma (PRP). Platelet poor plasma (1) and erythrocyte-enriched fractions (3) are not used for the production of PRP (@ by Arthrex, USA).

(BCVA) was determined using standard ETDRS charts at 4 meters. Moreover, slit lamp biomicroscopy including dilated fundus examination, SD-OCT scanning with volume and radial scans (SPECTRALIS HRA + OCT, Heidelberg Engineering, Heidelberg, Germany), microperimetry (MAIA, Centervue Inc., Fremont, CA, USA), and fundus photography (Optos P200Tx, Optos, Dunfermline, Scotland) was performed. Follow-up examinations took place 1 and 3 months postoperatively and included the identical workup.

\section{PRP preparation}

Immediately before surgery, $105 \mathrm{~mL}$ of whole blood of the respective patient was drawn into a syringe and mixed with $15 \mathrm{~mL}$ of citrate anticoagulant (ACD-A), resulting in a ratio of $1: 7$. After that, the anticoagulated blood was processed by the closed-circuit Arthrex Angel System (Arthrex, Naples, Florida, USA). This system processes anticoagulated blood in an automated preparation cycle. Using cell-specific wavelengths, the system is able to separate PRP, platelet-poor plasma, and red blood cells (into sterile compartments without a non-sterile intervention. Due to this special method of preparation and centrifugation, the resulting highly concentrated PRP is characterized by a low concentration of white blood cells (e.g., neutrophil granulocytes), thereby reducing the potential proinflammatory effects of neutrophils ( $\triangleright$ Fig. 1). This results in an 8.8-fold concentration of platelets in PRP compared to the concentration in whole blood.

\section{Surgical procedure}

All patients underwent a 23-gauge pars plana vitrectomy with peeling of both epiretinal tissue and the ILM if traction was evident on SD-OCT, according to the surgeon's judgement. If no traction was present, only induction of a posterior vitreous detachment was initiated over the optic disc and the posterior pole, and then continued peripherally. If performed, ILM peeling was facilitated by staining with MembraneBlue-Dual dye $0.125 \mathrm{mg}$

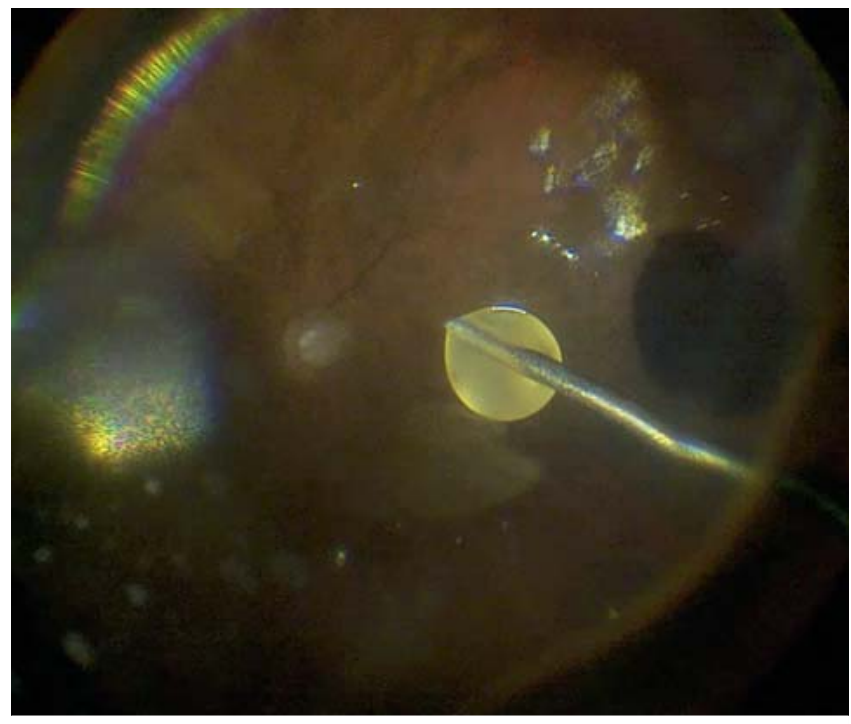

- Fig. 2 Intraoperative image of the application of highly concentrated platelet-rich plasma under air tamponade.

Brilliant Blue G and $0.75 \mathrm{mg}$ Trypan Blue, D.O.R.C., Zuidland, Netherlands). In all phakic patients, a combined phacovitrectomy with intraocular lens implantation was performed.

Under air tamponade, $0.1 \mathrm{~mL}$ PRP was applied to the posterior pole ( $\vee$ Fig. 2). Subsequently, all patients received air or gas tamponade. Postoperative resting in the supine position was ordered for the first 2 postoperative hours.

\section{Statistical Analysis}

Statistical analysis was performed using IBM SPSS Statistics, Version 25 (IBM Corporation, New York, USA). Descriptive data are displayed as the mean \pm standard deviation (SD). The Wilcoxon signed-rank test was performed to compare two related samples 
- Table 1 Clinical and surgical data.

\begin{tabular}{|c|c|c|c|c|c|c|c|c|}
\hline \multirow[t]{2}{*}{ ID } & & \multicolumn{2}{|c|}{ Lens status } & & \multicolumn{2}{|l|}{ Surgery } & \multicolumn{2}{|c|}{ BCVA (logMAR) } \\
\hline & & Preop & Postop & & Peeling of structures & PVD & Preop & 3 months FU \\
\hline 1 & $78 / \mathrm{M} / \mathrm{OD}$ & $\mathrm{IOL}$ & $\mathrm{IOL}$ & LHEP; HET & ERM; ILM & Present & 0.4 & 0.1 \\
\hline 2 & $81 / \mathrm{M} / \mathrm{OS}$ & Phakic & $\mathrm{IOL}$ & LHEP & None & Induced & 0.22 & 0.0 \\
\hline 3 & $57 / F / O D$ & Phakic & $\mathrm{IOL}$ & LHEP; HET & VC; ERM; ILM & Partial & 0.22 & 0.22 \\
\hline 4 & $67 / F / O D$ & Phakic & $\mathrm{IOL}$ & LHEP; HET & ERM; ILM & Partial & 0.22 & -0.1 \\
\hline 5 & $65 / \mathrm{M} / \mathrm{OS}$ & $\mathrm{IOL}$ & $\mathrm{IOL}$ & LHEP; HET & ERM; ILM & Present & 0.4 & 0.3 \\
\hline 6 & $71 / \mathrm{M} / \mathrm{OS}$ & Phakic & $\mathrm{IOL}$ & LHEP; HET & VC & Partial & 0.3 & 0.22 \\
\hline 7 & $61 / F / O D$ & Phakic & $\mathrm{IOL}$ & HET & VC; ERM; ILM & Partial & 0.22 & 0.1 \\
\hline 8 & $80 / \mathrm{M} / \mathrm{OD}$ & $\mathrm{IOL}$ & $\mathrm{IOL}$ & LHEP; HET & VC; ILM & Induced & 0.22 & 0.22 \\
\hline
\end{tabular}

BCVA, best-corrected visual acuity; ERM, epiretinal membrane; F, female; FU, follow-up; HET, hyperreflective epiretinal tissue; ILM, internal limiting membrane; IOL, intraocular lens; LHEP, lamellar hole-associated epiretinal proliferation; M, male; OD, right eye; OS, left eye; PVD, posterior vitreous detachment; VC, vitreous cortex; VRI, vitreoretinal interface

- Table 2 Spectral-domain optical coherence tomography findings pre- and postoperatively.

\begin{tabular}{|c|c|c|c|}
\hline & & Preoperatively $(n=8)$ & Postoperatively $(n=8)$ \\
\hline \multirow{8}{*}{$\begin{array}{l}\text { Spectral-do- } \\
\text { main optical } \\
\text { coherence } \\
\text { tomography }\end{array}$} & Vitreomacular Interface & & \\
\hline & HET & $7(87.5 \%)$ & $0(0 \%)$ \\
\hline & LHEP & $7(87.5 \%)$ & $1(12.5 \%)$ \\
\hline & Associated intraretinal signs & & \\
\hline & Foveal bump & $1(12.5 \%)$ & $1(12.5 \%)$ \\
\hline & EZ defect & $4(50 \%)$ & $2(25 \%)$ \\
\hline & Central macular thickness & & \\
\hline & Mean \pm SD (range) $\mu \mathrm{m}$ & $301.3 \pm 27.23(261-348)$ & $319.6 \pm 25.6(382-357)$ \\
\hline
\end{tabular}

HET, hyperreflective epiretinal tissue; LHEP, lamellar hole-associated epiretinal proliferation; EZ, ellipsoid zone

(BCVA; data of microperimetry). A p value of $<0.05$ was considered to indicate statistical significance.

\section{Results}

Patient age ranged between 58 and 81 years with a mean of $70 \pm 9$ years (median 69 years). Five patients were male, three patients were female. There were five right and three left eyes. Main clinical data of all patients at baseline and follow-up as well as surgical characteristics are summarized in $>$ Table 1 .

Preoperatively, five of eight eyes were phakic and three of eight eyes were pseudophakic. All phakic eyes underwent vitrectomy combined with phacoemulsification and implantation of an intraocular lens.

\section{Functional Outcomes}

Preoperatively, the mean BCVA was $0.28 \pm 0.08 \log M A R$ (median 0.22 ; range $0.4-0.22$ ) corresponding to 20/32 Snellen. Following vitrectomy with PRP at 3 months, mean BCVA increased to $0.12 \pm 0.14 \log M A R$ (median 0.1 ; range $-0.1-0.3$ ) corresponding to $20 / 25$ Snellen, resulting in a significant visual acuity improvement ( $p=0.03$, Wilcoxon test). There was no patient who had reduced visual acuity compared to the preoperative status.

Microperimetry showed a preoperative mean threshold of $24.13 \pm 1.96 \mathrm{~dB}$ (median 23.8, range 21.0-26.8), which remained unchanged at 3 months postoperatively with $23.7 \pm 1.54 \mathrm{~dB}$ (median 23.5; range 22.10-26.10; $p=0.46$ ). Fixation stability values $\mathrm{P} 1$ and $\mathrm{P} 2$ also showed no significant change from the P1 median $85 \pm 31 \%$ preoperatively to $89 \pm 27 \%$ at 3 months follow-up, and the P2 median $96 \pm 15 \%$ preoperatively to $99 \pm 14 \%$ ( $p=0.8$, Wilcoxon test). Subjective complaints such as metamorphopsia decreased in all patients ( 8 of 8 ) at month 3 .

\section{Morphological Outcomes}

Preoperatively, all patients fulfilled the three mandatory criteria for LMH on SD-OCT, presenting with an irregular foveal contour, a foveal cavity with undermined edges, and a sign of foveal tissue loss. In addition, hyperreflective epiretinal tissue was found in 7 of 8 eyes, as summarized in $>$ Table $\mathbf{2}$, along with other OCT characteristics. 


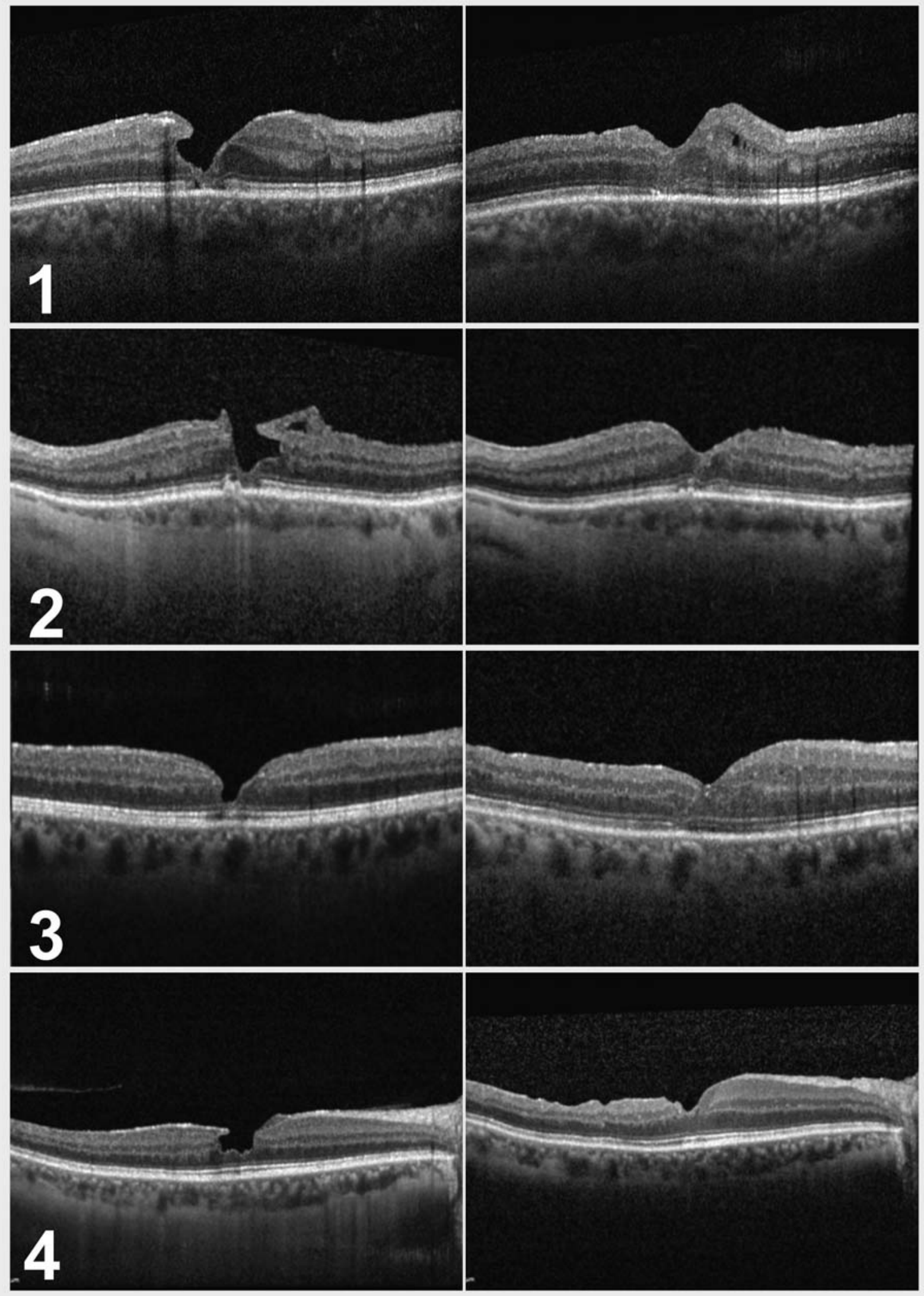

- Fig. 3 Spectral-domain optical coherence tomography (SD-OCT) of Patients 1-4. Left side: SD-OCT at baseline. Right side: SD-OCT at 3 months follow-up. 


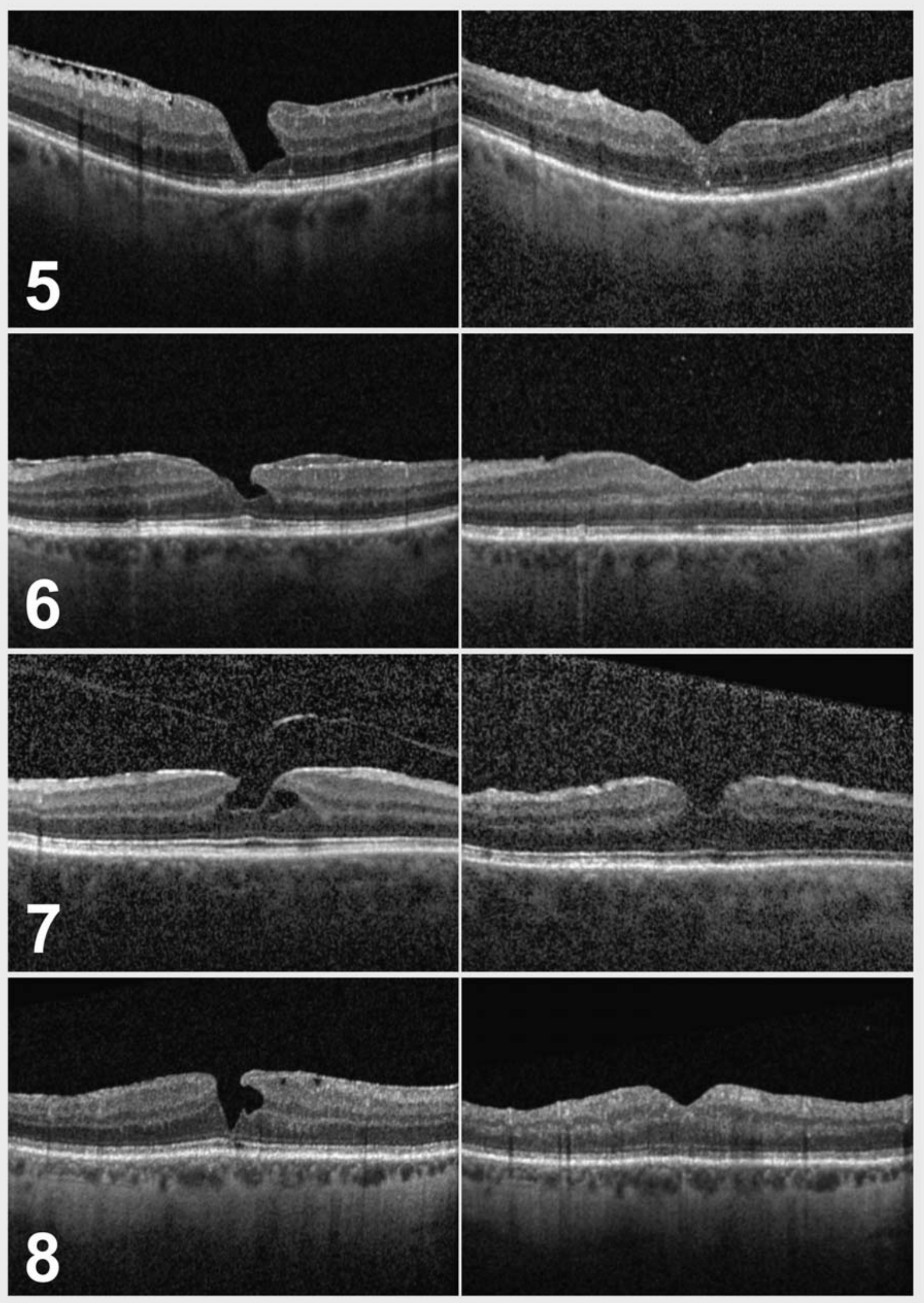

Fig. 4 Spectral-domain optical coherence tomography (SD-OCT) of Patients 5-8. Left side: SD-OCT at baseline. Right side: SD-OCT at 3 months follow-up. 
Postoperatively, the foveal contour showed an improved configuration in all cases as shown in - Fig. $\mathbf{3}$ and $\mathbf{4}$ with a complete closure of the $\mathrm{LMH}$ and a restored presentation of the ellipsoid zone in two cases ( $\triangleright$ Fig. 3: 1 and 2). Reorganization of the foveal configuration could be observed as soon as the endotamponade was dissolved.

In all patients, central macular thickness in the $1 \mathrm{~mm}$ circle of an overlying ETDRS grid increased at first follow-up and stabilized again on a slightly elevated level after 3 months due to the closed lamellar defect $(301.3 \pm 27.23 \mu \mathrm{m} ; 261-348)$ preoperatively to $319.6 \pm 25.6 \mu \mathrm{m}(382-357)$ at 3 months follow-up $(p=0.04)$.

\section{Discussion}

Management of patients with LMH varies widely among ophthalmologists, and a plethora of clinical recommendations for the conservative or surgical management of LMH has been published [10]. Long-term follow-up studies have shown that over the course of 5 years, LMHs tend to progress morphologically in onethird of patients, whereas BCVA remains stable in most patients or only decreases slowly [11]. However, the progression to a disruption in the ellipsoid zone results in significantly worse outcomes, even with surgical intervention [12]. Thus, an earlier intervention that can stabilize the foveal configuration may be advantageous in certain cases. Nevertheless, most of the available studies have only shown a stabilization or possible moderate gain in visual acuity after vitrectomy with ILM peeling in progressive LMHs [10]. Recent publications report similar results with the so-called LHEP embedding technique, in which LHEP becomes embedded in the foveal defect during vitrectomy [13]. Moreover, severe complications such as a progression to a FTMH or retinal detachment after vitrectomy may occur. Hence, it is currently common practice to defer surgical intervention until a marked decrease in BCVA or an increase in the patient's complaints is noted.

The use of autologous PRP in macular surgery has been described since the 1990s in patients with FTMHs [14]. Since then, autologous blood serum or plasma has been used in different retinal diseases such as traumatic, persistent, and recurrent FTMHs or in optic disc pit maculopathy [15-18].

PRP is extracted from autologous, anticoagulated blood by centrifugation. The main components of PRP are thrombocytes (blood platelets) that serve as a natural reservoir for numerous growth factors that play an important role in wound healing, such as epidermal growth factor (, nerve growth factor, platelet-derived growth factor, transforming growth factor, basic fibroblast growth factor, or vascular endothelial growth factor $[19,20]$.

This case series shows a beneficial outcome in patients with $\mathrm{LMH}$ that were treated by vitrectomy and additional application of highly concentrated PRP to the macular region. In contrast to other studies, membrane peeling was only performed when tractional membranes were evident in SD-OCT or intraoperatively. Of note, this had no influence on the LMH closure rate. Even in eyes where only vitrectomy with induction of a posterior vitreous detachment and additional PRP application was performed, foveal configuration recovered and BCVA as well as metamorphopsia improved.
The hypothesis behind these favorable results might be an interaction between Mueller cells, the predominant glial cell type of the neuroretina, and PRP components, as mentioned above. The platelets in PRP are activated through contact with disintegrated neuroretinal tissue of the fovea and by the release of their growth factors. This leads to a stimulation of Mueller cells and triggers their proliferation and migration [21]. As end stages of LMH show a pronounced substance defect and loss of Mueller cells, accompanied by a disruption in the ellipsoid zone, a surgical treatment, which is supposed to affect Mueller cells, seems to be reasonable in earlier stages where there are still enough vital Mueller cells for the PRP cell interaction.

Our study is mainly limited by the low number of participants and the lack of a control group. Moreover, the confounding effect of phacoemulsification and intraocular lens implantation on the development of visual acuity cannot be estimated, as all phakic patients were treated by phacovitrectomy. Based on unequivocal anatomical results on SD-OCT, our study, however, clearly indicates positive effects of the combined use of vitrectomy and application of highly concentrated PRP for LMH surgery.

The surgical intervention in LMHs, especially in degenerative $\mathrm{LMHs}$, is widely discussed. $\mathrm{LMHs}$ have the propensity to progress and develop defects in the ellipsoid layer, which causes further visual deterioration. This case series shows that vitrectomy with the adjunct of highly concentrated PRP may positively affect both the morphology and function in LMHs. In addition, a regeneration of the ellipsoid zone was observable in our case series. Most importantly, in the cases studied, there was no evidence of safety issues for the use of PRP. Additional studies with a longer follow-up as well as a higher number of patients are warranted to confirm these promising initial results.

\section{Acknowledgements}

Funding/Support: This research did not receive any specific grant for funding from agencies in the public, commercial, or not-for-profit sector. The Arthrex Angel system was provided by Arthrex, Naples, Florida, USA. None of the authors has a financial interest to declare regarding the content of this manuscript.

\section{Conflict of Interest}

The authors declare that they have no conflict of interest.

\section{References}

[1] Gass JD. Lamellar macular hole: a complication of cystoid macular edema after cataract extraction. Arch Ophthalmol 1976; 94: 793-800. doi:10.1001/archopht.1976.03910030391008

[2] Bottoni F, Deiro AP, Giani A et al. The natural history of lamellar macular holes: a spectral domain optical coherence tomography study. Graefes Arch Clin Exp Ophthalmol 2013; 251: 467-475. doi:10.1007/s00417012-2044-2

[3] Hubschman JP, Govetto A, Spaide RF et al. Optical coherence tomography-based consensus definition for lamellar macular hole. $\mathrm{Br}$ J Ophthalmol 2020; 104: 1741-1747. doi:10.1136/bjophthalmol-2019-315432

[4] Pang CE, Spaide RF, Freund KB. Epiretinal proliferation seen in association with lamellar macular holes: a distinct clinical entity. Retina 2014; 34: 1513-1523. doi:10.1097/iae.0000000000000163 
[5] Compera D, Schumann RG, Cereda MG et al. Progression of lamellar hole-associated epiretinal proliferation and retinal changes during long-term follow-up. $\mathrm{Br}$ J Ophthalmol 2018; 102: 84-90. doi:10.1136/ bjophthalmol-2016-310128

[6] Marques MF, Rodrigues S, Raimundo M et al. Epiretinal Proliferations Associated with Lamellar Macular Holes: Clinical and Surgical Implications. Ophthalmologica 2018; 240: 8-13. doi:10.1159/000486691

[7] Schumann RG, Hagenau F, Guenther SR et al. Premacular Cell Proliferation Profiles in Tangential Traction Vitreo-Maculopathies Suggest a Key Role for Hyalocytes. Ophthalmologica 2019; 242: 106-112. doi:10.1159/000495853

[8] Figueroa MS, Noval S, Contreras I. Macular structure on optical coherence tomography after lamellar macular hole surgery and its correlation with visual outcome. Can J Ophthalmol 2011; 46: 491-497. doi:10.1016/j.jcjo.2011.09.011

[9] Gonzalez A, Amin S, Iqbal O et al. Use of Autologous Platelets for LamelIar Macular Hole Repair. Case Rep Ophthalmol Med 2019; 2019: 1471754. doi:10.1155/2019/1471754

[10] Danielescu C, Stanca HT, Balta F. The Management of Lamellar Macular Holes: A Review. J Ophthalmol 2020; 2020: 3526316. doi:10.1155/ 2020/3526316

[11] Purtskhvanidze K, Balken L, Hamann T et al. Long-term follow-up of lamellar macular holes and pseudoholes over at least 5 years. Graefes Arch Clin Exp Ophthalmol 2018; 256: 1067-1078. doi:10.1007/ s00417-018-3972-2

[12] Schumann RG, Compera D, Schaumberger MM et al. Epiretinal membrane characteristics correlate with photoreceptor layer defects in lamellar macular holes and macular pseudoholes. Retina 2015; 35: 727-735. doi:10.1097/iae.0000000000000375

[13] Takahashi K, Morizane Y, Kimura S et al. Results of lamellar macular holeassociated epiretinal proliferation embedding technique for the treat- ment of degenerative lamellar macular hole. Graefes Arch Clin Exp Ophthalmol 2019; 257: 2147-2154. doi:10.1007/s00417-019-04425-9

[14] Liggett PE, Skolik DS, Horio B et al. Human autologous serum for the treatment of full-thickness macular holes. A preliminary study. Ophthalmology 1995; 102: 1071-1076. doi:10.1016/s0161-6420(95)30909-8

[15] Gaudric A, Massin P, Paques M et al. Autologous platelet concentrate for the treatment of full-thickness macular holes. Graefes Arch Clin Exp Ophthalmol 1995; 233: 549-554. doi:10.1007/bf00404704

[16] Rosenthal G, Bartz-Schmidt KU, Walter P et al. Autologous platelet treatment for optic disc pit associated with persistent macular detachment. Graefes Arch Clin Exp Ophthalmol 1998; 236: 151-153. doi:10.1007| s004170050056

[17] Chow DR, Williams GA, Trese MT et al. Successful closure of traumatic macular holes. Retina 1999; 19: 405-409. doi:10.1097/00006982199909000-00006

[18] Purtskhvanidze K, Frühsorger B, Bartsch S et al. Persistent Full-Thickness Idiopathic Macular Hole: Anatomical and Functional Outcome of Revitrectomy with Autologous Platelet Concentrate or Autologous Whole Blood. Ophthalmologica 2018; 239: 19-26. doi:10.1159/ 000481268

[19] Werner S, Grose R. Regulation of wound healing by growth factors and cytokines. Physiol Rev 2003; 83: 835-870. doi:10.1152/physrev.2003. 83.3.835

[20] Andresen JL, Ledet T, Ehlers N. Keratocyte migration and peptide growth factors: the effect of PDGF, bFGF, EGF, IGF-I, aFGF and TGF-beta on human keratocyte migration in a collagen gel. Curr Eye Res 1997; 16: 605-613. doi:10.1076/ceyr.16.6.605.5081

[21] Burmeister SL, Hartwig D, Limb GA et al. Effect of various platelet preparations on retinal muller cells. Invest Ophthalmol Vis Sci 2009; 50 : 4881-4886. doi:10.1167/iovs.08-3057 